\title{
CONTROLE DE CONVENCIONALIDADE: SUBSÍDIOS PARA A EDIFICAÇÃO DE UM ORDENAMENTO JURÍDICO VOLTADO PARA A PROTEÇÃO DOS DIREITOS HUMANOS
}

\author{
CONVENTIONALITY CONTROL: GRANTS FOR CONSTRUCTION OF \\ JURISDICTION FOCUSED ON PROTECTING HUMAN RIGHTS
}

\begin{abstract}
Resumo
A afirmação internacional dos direitos humanos é temática muito debatida atualmente, em razão, principalmente, das diversas violações sofridas por estes direitos nos últimos anos, como o ocorrido na Guiné-Bissau após o golpe de Estado em abril de 2012 e os acontecimentos verificados na Síria após o considerável aumento das atrocidades cometidas pelas forças do regime de Bashar $\mathrm{Al}$ Assad. Em razão disso a ordem internacional de proteção dos direitos humanos tem se desenvolvido consideravelmente nos últimos anos. Contudo, é preciso que haja uma conformação desta ordem internacional com as legislações domésticas. Por isso, o presente trabalho visa analisar a teoria do Controle de Convencionalidade e suas contribuições para a consolidação de um direito comum de base humanitária no âmbito da América latina. Para tanto, foi realizada uma pesquisa bibliográfica, com método de abordagem indutivo e de procedimento monográfico. Como resultado, se constatou que as grandes contribuições da teoria do Controle de Convencionalidade para a construção de um direito comum humanitário latino-americano foram a facilitação do diálogo internacional através da atuação dos juízes singulares nacionais, a implementação de uma tutela multinível, bem como a legitimação e a imputação de responsabilidade internacional aos Estados violadores dos direitos internacionalmente pactuados.
\end{abstract}

Palavras-chave: Direito internacional dos direitos humanos. Teoria do Controle de Convencionalidade. Ordenamento jurídico brasileiro.

\section{Abstract}

The international human rights statement is a currently much debated topic, mainly because the severe violations suffered by those human rights in recent years, as occurred at GuineaBissau after the April 2012 coup d'Etat and the events occurring in Syria after the considerable increase in atrocities committed by the forces of the Bashar Al Assad regime. For this reason, the international protection of human rights order has been considerably developed in the last few years. However, is necessary a conformation of this international order with the domestic legislation. Therefore, the present review pretends to analyze the Control of Conventionality theory and its contributions to the consolidation of a Common Law with a humanitarian ground in latin America. For this, a literature search was conducted, with intuitive approach method and manographic procedure. As a result, it was found that the major contributions of Control of Conventionality theory, for the construction of a humanitarian Latin America common Law, were the facilitation of international dialogue through the performance of the national individual judges, the implementation of a multilevel 
protection, as well as the legitimacy and the attribution of international responsibility to States that violates the internationally agreed rights.

Keywords: International Law of Human Rights. Control of Conventionality Theory. Brazilian Legal System

\section{INTRODUÇÃO}

A afirmação internacional dos direitos humanos é temática muito debatida atualmente, em razão, principalmente, das diversas violações a tais direitos verificadas nos últimos anos, como o ocorrido na Guiné-Bissau após o golpe de estado de abril de 2012 e o caso Síria após o progressivo aumento das atrocidades cometidas pelas forças do regime de Bashar Al Assad.

Por isso, os organismos nacionais e internacionais, como a Organização das Nações Unidas - ONU, não vêm medindo esforços para minimizar esta infeliz realidade, impulsionando diversas campanhas de promoção aos direitos humanos: Campanha Mulheres e Direito, Declare-se Defensor dos Direitos Humanos, Education First, etc., bem como tomando medidas providenciais, como foi a recente representação de entidades gaúchas junto à Comissão Interamericana de Direitos Humanos em razão das extremadas condições dos apenados do Presídio Central de Porto Alegre.

O Brasil, por exemplo, tem empenhado-se bastante no plano internacional para integrar essa nova ordem internacional de proteção aos direitos humanos, ratificando e colocando em vigor praticamente todos os tratados internacionais mais significativos, como a Convenção para Prevenção e a Repressão do Crime de Genocídio (1948), dentre tantos outros.

$\mathrm{Na}$ mesma linha, a Constituição Federal Brasileira de 1988, a chamada "Constituição Cidadã”, estabeleceu um marco para o processo de redemocratização brasileiro e para a institucionalização desses direitos humanos, consagrando de maneira inédita um enorme elenco de direitos e garantias fundamentais.

Mas ainda é preciso vencer as barreiras nacionais e conformar estes dois âmbitos, de forma a construir ordenamentos coerentes com essa nova ordem mundial instaurada no período pós Segunda Guerra Mundial e partir para a consolidação do Estado Democrático e Humanitário de Direito. E é justamente a isto que se propõe o controle de convencionalidade 
das leis: promover uma conformação da produção normativa interna com a ordem humanitária internacional.

Nesse sentido, o presente estudo visa analisar em que a teoria do Controle de Convencionalidade pode efetivamente contribuir para esta conformação entre direito interno e internacional, ou seja, investigar como a teoria do Controle de Convencionalidade pode contribuir para a efetivação do diálogo entre os sistemas normativos domésticos e os compromissos internacionalmente assumidos dentro do contexto latino-americano.

Para tanto, foi realizada uma pesquisa qualitativa de caráter exploratório. O método de pesquisa adotado foi o bibliográfico, com enfoque nas principais fontes do direito (norma, doutrina e jurisprudência) e com método de abordagem indutivo, haja vista que pretende deduzir uma verdade geral a partir de dados individualizados, "chegando a conclusões cujo conteúdo é mais amplo do que as premissas nas quais se basearam" (MARCONI; LAKATOS, 2010, P. 68). O método procedimental utilizado, por sua vez, foi o monográfico.

Contudo, a fim de se evitar desentendimentos, é fundamental revisar alguns conceitos e percepções antes de se adentrar no cerne da questão, em especial no tocante as definições e origens desse Controle de Convencionalidade.

\section{DEFINIÇÕES E ORIGENS}

A formação da Organização das Nações Unidas em 1945 e a ratificação da Declaração Universal dos Direitos Humanos em 1948 impulsionaram o que conhecemos hoje como direito internacional dos direitos humanos. Neste contexto pós Segunda Guerra se começa a observar uma reconstrução dos direitos humanos "como paradigma e referencial ético a orientar a ordem internacional contemporânea" (PIOVESAN, 2012, p. 184), já que tal massacre rompeu com todos os parcos valores humanitários até então estabelecidos, tornando os seres humanos supérfluos e descartáveis e, consequentemente, negando o valor da pessoa humana como valor fonte de direito. Essa reviravolta valorativa representa exatamente uma quebra dos ideais totalitários e a reconstrução da noção de direitos humanos a partir da ideia de que o maior dos direitos é o direito a se ter direitos, isto é, o direito de ser sujeito de direitos. 
Tal reconstrução valorativa calcada na ideia de que o sujeito deixa de ser objeto e passa a ser sujeito de direitos trouxe de uma vez por todas para o centro do debate a questão da delimitação da soberania estatal. A partir desse momento passou-se a compreender que a proteção aos direitos humanos não poderia mais ficar adstrita unicamente ao âmbito doméstico e que tais direitos passariam a deter legítimo interesse internacional, uma vez que na referida conjuntura o grande agressor era o próprio Estado. Essa nova visão intensificou os debates concernentes aos Tribunais Internacionais e suas respectivas jurisdições, efeitos coercitivos, etc.

E foi justamente nesse contexto que foi dado inicio aos debates concernentes ao que viria a ser a Teoria do Controle de Convencionalidade. Temática muito pouco explorada pelos doutrinadores brasileiros mas que já vem sendo debatida no âmbito da Corte Interamericana de Direitos Humanos desde, pelo menos, o ano de 2006.

Alcalá (2012) assegura que o conceito de controle de convencionalidade - muito embora seja uma ideia já utilizada há várias décadas no sistema europeu de proteção aos direitos humanos para explicitar a função dos juízes nacionais de velar pelo respeito e pela garantia destes direitos como standards mínimos - foi estabelecido formalmente pela Corte Interamericana, pela primeira vez e de forma unânime, na sentença do conhecido caso "Almonacid Arellano y otros vs. Chile", de setembro de 2006:

\footnotetext{
124. La Corte es consciente que los jueces y tribunales internos están sujetos al imperio de la ley y, por ello, están obligados a aplicar las disposiciones vigentes en el ordenamiento jurídico. Pero cuando un Estado ha ratificado un tratado internacional como la Convención Americana, sus jueces, como parte del aparato del Estado, también están sometidos a ella, lo que les obliga a velar porque los efectos de las disposiciones de la Convención no se vean mermadas por la aplicación de leyes contrarias a su objeto y fin, y que desde un inicio carecen de efectos jurídicos. En otras palabras, el Poder Judicial debe ejercer una especie de 'control de convencionalidad' entre las normas jurídicas internas que aplican en los casos concretos y la Convención Americana sobre Derechos Humanos. En esta tarea, el Poder Judicial debe tener en cuenta no solamente el tratado, sino también la interpretación que del mismo ha hecho la Corte Interamericana, intérprete última de la Convención Americana.
}

A partir daí não foram poucas as decisões que abordaram essa nova temática. Alcalá (2012) inclusive destaca que foi no caso "Trabajadores Cesados del Congreso vs. Perú" que a Corte Interamericana melhor exteriorizou a teoria do controle de convencionalidade:

128. Cuando un Estado ha ratificado un tratado internacional como la Con vención Americana, sus jueces también están sometidos a ella, lo que les obliga a velar porque el efecto útil de la Convención no se vea mermado o anulado por la aplicación de leyes contrarias a sus disposiciones, objeto y fin. En otras palabras, los 
órganos del Poder Judicial deben ejercer no sólo un control de constitucionalidad, sino también 'de convencionalidad' ex officio entre las normas internas y la Convención Americana, evidentemente en el marco de sus respectivas competencias $\mathrm{y}$ de las regulaciones procesales correspondientes.

Sem dúvida estas foram as duas mais importantes manifestações da Corte Interamericana sobre a teoria do controle de convencionalidade. E conforme sustentam Junior e Campos (2011), é possível perceber uma clara evolução entre os dois pronunciamentos: no caso Almonacid Arellano a Corte faz menção ao dever do Poder Judiciário de realizar alguma forma de controle de convencionalidade; já no caso dos Trajadores Cesados del Congreso a Corte faz referência expressa à realização do controle de convencionalidade, consolidando expressamente a ideia do referido controle. Ou seja, a evolução conceitual trazida pelas decisões da Corte denota que se partiu da necessidade de formular uma teoria capaz de adaptar a legislação local aos compromissos internacionais humanitários para a o dever de aplicar tal teoria.

E com a análise dos dois casos, é possível extrair que a ideia central do controle de convencionalidade das leis consolidada pela Corte é a de que não podem as leis locais, mesmo coerentes com o ordenamento constitucional local, mitigar o efeito útil das disposições, do objeto e das finalidades das Convenções pelos Estados ratificadas. Ou melhor dizendo, não pode a legislação doméstica ir de encontro às obrigações internacionais.

Também com intuito de trazer uma definição mais estável, Mazzuoli (2009), ao proceder uma comparação entre o controle de constitucionalidade e o controle de convencionalidade das leis destaca que este pode ser caracterizado como a compatibilização da produção normativa doméstica com os tratados de direitos humanos ratificados pelo governo e em vigor no país.

No mesmo sentido, o controle de convencionalidade ainda pode ser definido "como una herramienta sumamente eficaz para el respeto, la garantia y la efectivización de los derechos descritos por el Pacto [de San Jose da Costa Rica]” (SAGÜES, 2010, P. 118).

Revela uma nova epistemologia jurídica onde é possibilitado ao sujeito de direitos uma proteção para além das amarras estatais, consubstanciando a idéia de que o "Estado não é o lugar único do Poder político, tampouco fonte exclusiva da produção do direito" (WOLKMER, 2001, p. 203). Aliás, Santos afirma que "na realidade, o Estado nunca deteve o monopólio do direito" (2000, p. 171). Só é assim visualizado atualmente pois é fruto e instrumento da histórica relação de dominação entre dominantes e dominados. O controle de convencionalidade quer justamente dar abrigo aos que não são servidos pelo direito estatal. 
Conforme propõe Jinesta (2012), o controle de convencionalidade supõe inclusive uma revisão na teoria das fontes do Direito, uma vez que tem um potencial para readaptar uma série de categorias dogmáticas e para possibilitar o surgimento de outras totalmente distintas e inovadoras. Tanto assim é que, segundo sustenta o autor, coloca em xeque até mesmo a supremacia exclusiva da Constituição dentro do ordenamento jurídico.

Enfim, é, em suma, uma construção da jurisprudência da Corte Interamericana de Direitos Humanos com intuito de conferir uma maior efetividade à proteção aos direitos humanos no âmbito de sua jurisdição.

Segundo aponta Saguiés (2011), a Teoria do Controle de Convencionalidade foi gestada em dois níveis: a) um primeiro controle chamado de inter (ou supra) nacional de convencionalidade que já vem sendo exercido pela Corte há mais de uma década e que reputa inválidas as normas de direito interno opostas ao Pacto San José da Costa Rica; b) e um segundo controle denominado de nacional de convencionalidade ou, um controle "desde abajo" (SAGÜÉS, 2011, P. 382), que surge a partir de 2006 com o caso Almonacid Arellano e que vai obrigar os juízes nacionais a não aplicar, eles mesmos, as normas locais opostas ao Pacto de San José da Costa Rica e à sua própria jurisprudência.

A primeira forma de controle tem como caso principal o La última tentación de Cristo, que reputou violadora do Pacto uma cláusula da Constituição Chilena que tratava de censura televisiva. Já a segunda forma é embasada pelo caso Almonacid Arellano e é a forma de controle de convencionalidade analisada daqui para frente.

Mas conforme assegura Saguiés (2011), o controle de convencionalidade, fora do continente europeu e ainda de forma relativamente embrionária, parte de uma série de votos singulares do juiz da Corte Interamericana Sérgio Garcia Ramirez, nos casos Myrna Mack Change (2003) e Tibi (2004). Porém, conforme acima mencionado, é formulado pelo corpo pleno e de forma explícita somente em Almonacid Arellano (2006), considerandos 124 e 125. Seus recortes complementares são traçados basicamente por mais duas sentenças, que é o caso dos Trabajadores Cesados del Congreso (2006), considerando 128, e Radilla Pacheco (2009), nos considerandos 338 a 340.

A partir de então, segundo o autor, diversos foram os pronunciamentos da Corte a respeito da temática, como são os casos La Cantuta (2006), considerando 173, Boyce vs. Barbados (2007), considerando 78, Fermín Ramirez y Raxcacó Reyes (2008), considerando 63, Heliodoro Portugal (2008), considerando 180/1, Manuel Cepeda Vargas (2010), considerando 208 e nota 307, Comunidad Indígena Xákmok Kásek (2010), considerando 311, Fernández Ortega (2010), considerando 237, Rosendo Cantú (2010), considerando 219 e 220, 
Ibsen Cárdenas y outro (2010), considerando 202, Velez Loor (2010), considerando 287, Gomes Lund (2010), considerando 176 e Cabrera Garcia-Montiel Flores (2010), considerando 225 .

E toda esta gama de casos consolida a existência e a afirmação de um direito processual internacional consuetudinário, que a cada decisão consolida ainda mais esta inovadora teoria do controle de convencionalidade e, consequentemente, a proteção transnacional dos direitos humanos.

Os fundamentos jurídicos do controle de convencionalidade encontram-se nos arts. $1^{\circ}$ e $2^{\circ}$, bem como nos arts. 67 e 69 da Convenção Americana de Direitos Humanos.

\begin{abstract}
El control de convencionalidad emana de las dos obligaciones erga omnes que los estados partes asumieron libre y voluntariamente al ratificar la Convención Americana sobre Derechos Humanos, las contenidas en los artículos $1^{\circ}$ y $2^{\circ}$ de ella, por una parte, como asimismo por el reconocimiento, también libre y voluntario, de la jurisdicción vinculante de las sentencias de la Corte Interamericana de Derechos Humanos, las que constituyen obligaciones de resultado para el Estado Parte, de acuerdo a los artículos 67 a 69 de la misma convención, como por último del reconocimiento de la Corte interamericana como intérprete auténtica y final de la CADH (ALCALÁ, 2012, P. 65).
\end{abstract}

Ou seja, o controle de convencionalidade deriva, de um lado, das obrigações erga omnes assumidas livre e voluntariamente pelos signatários da Convenção Americana, e, de outro, pela jurisdição vinculante das sentenças da Corte. Frise-se, porém, que segundo sustenta Sagüés (2011), a convencionalidade das leis não se restringe à tutela da Convenção Americana de Direitos Humanos, ou no plano europeu, ao Tratado de Lisboa ou ao Convênio Europeu de Direitos Humanos, podendo também haver controle nos âmbitos de outros tratados, como nos pactos internacionais de direitos civis e políticos e de direitos econômicos e sociais. Obviamente no âmbito dos primeiros a percepção da existência do controle é muito mais nítida, haja vista que ditam resoluções com pretensões jurídicas dotadas de obrigatoriedade, enquanto os últimos são ainda bastante embrionários.

Tanto assim é que o art. $1^{\circ}$ da Convenção Americana de Direitos Humanos determina aos Estados pactuantes a obrigação jurídica de respeitar e garantir todos os direitos por ela assegurados.

E lembrando que as obrigações contidas nos pactos e convenções internacionais, com ainda maior razão se referentes à assuntos relacionados com os direitos humanos e, sobretudo, se o Estado é signatário da Convenção de Viena sobre Direito dos Tratados, constituem para os magistrados direito diretamente aplicável e com preferência em relação as normas internas. Isso se deve, basicamente, em atenção aos artigos 26, 27 e 31.1 da desta Convenção. $\mathrm{O}$ art. 26 
por estabelecer que todo tratado em vigor obriga seus signatários e deve ser por eles cumprido de boa-fé. $\mathrm{O}$ art. 27 , ao seu tempo, por afirmar que não pode a parte signatária invocar direito interno para inobservar cláusula de tratado internacional. Já o art. 31.1, por estabelecer que o tratado deve ser interpretado também com boa-fé e em conformidade com o sentido comum atribuível aos termos da convenção em seu contexto e à luz do seu objetivo e finalidade.

$\mathrm{O}$ art. $2^{\circ}$ da Convenção Americana, por sua vez, estabelece o comprometimento com a adoção de todas as medidas legislativas ou de qualquer outra natureza que forem necessárias para tornar efetivos os direitos e liberdades estabelecidos no art. $1^{\circ}$. Isso quer dizer que deve o Estado signatário adequar seu direito interno às disposições convencionais, sempre com intuito de garantir os direitos por ela consagrados, indo exatamente ao encontro do que preceitua o art. 27 da Convenção de Viena.

Essa adequação do ordenamento jurídico interno, segundo sustenta Alcalá (2012), deve se dar desde o mais singelo ato administrativo até o plano constitucional. Todo Estado parte da Convenção deve eliminar completamente de seu ordenamento jurídico e também está impedido de criar leis ou quaisquer outras espécies normativas que vulnerem o standard mínimo estabelecido internacionalmente. A contrario sensu, segundo assegura o mesmo autor, se a legislação doméstica estiver para além dos padrões mínimos convencionais, ou seja, for mais favorável à proteção da pessoa humana, obviamente não deverá o Estado adequar sua estrutura normativa interna. Essa ponderação normativa deve sempre levar em consideração a principiologia disposta no art. 29 da Convenção Americana, assim como no art. $5^{\circ}$ Pacto Internacional sobre Direitos Civis e Políticos, "dónde están expresamente contenidos los principios 'favor persona' o 'pro homine' y de progresividad" (ALCALÁ, 2012, P. 69).

Tal conformação entre o ordenamento doméstico e o convencional prevista neste art. $2^{\circ}$ da Convenção Americana de Direitos Humanos decorre da moderna lógica já anteriormente explicitada de limitação da própria soberania em prol da coletividade, ou ainda, em favor de um bem maior que é o respeito à dignidade da pessoa humana.

Como anteriormente citado, para tratar da estrutura normativa do controle de convencionalidade no âmbito da América latina é indispensável mencionar também os artigos 67 a 69 da Convenção Americana de Direitos Humanos. Enquanto os artigos $1^{\circ}$ e $2^{\circ}$ estabelecem a obrigação de respeitar e garantir os direitos elencados na Convenção e a adequação à mesma do ordenamento jurídico interno, os artigos 67, 68 e 69 tratam da obrigação jurídica do Estado parte de cumprir as decisões proferidas nos julgamentos da Corte Interamericana de Direitos Humanos. 
$\mathrm{O}$ art. 67 estabelece que a sentença prolatada pela Corte é definitiva e inapelável, podendo a Corte a pedido das partes, no máximo, reinterpretá-la nos casos de divergência relativa ao alcance ou sentido. Já o art. 68 com propriedade preceitua que competem aos Estados partes cumprir a decisão da Corte em todos os casos em que forem partes. O art. 69, por fim, estabelece que da sentença da Corte devem ser as partes notificadas e os signatários da Convenção participados.

Enfim, são manifestos os marcos normativos impulsionadores do controle de convencionalidade no contexto americano, o que deslegitima o argumento de que essa espécie de controle da legislação doméstica seria resultado de uma simples construção jurisprudencial. Deixa evidente, destarte, a densidade legal desse tão importante discurso humanitário.

\section{CARACTERÍSTICAS}

Diversas são as características dessa nova espécie de controle da legislação interna que merecem destaque. Mas antes de qualquer coisa é necessário discorrer a respeito dos efeitos do controle de convencionalidade.

Segundo assegura Saguiés (2011) o controle de convencionalidade pode ter dois efeitos: repressivo e um positivo.

O primeiro, também chamado de efeito destrutivo, ocorre quando a norma interna oposta à Convenção ou à jurisprudência da Corte Interamericana não é aplicável ao caso concreto ou é inválida para o mesmo caso. Nesse sentido assinalou a Corte Interamericana no já mencionado caso Almonacid Arellano, no seu considerando 123, que se um Estado mantém em seu ordenamento jurídico normas contrárias à Convenção compete ao judiciário local abster-se de aplicá-la. E ainda neste mesmo caso decidiu a Corte, de forma ainda mais inovadora, segundo Saguiés (2011), que esta norma contrária aos ditames convencionais carece inclusive de efeitos jurídicos desde sua entrada em vigor. Isto é, nem chega a ser afastada.

No segundo efeito, também denominado de efeito construtivo, o poder judiciário local deve praticar e fazer funcionar o direito nacional de acordo com as regras convencionais e com o entendimento da Corte. Essa postura requer releituras do ordenamento jurídico nacional, bem como a diferenciação entre interpretações convencionais e inconvencionais do 
direito doméstico para, assim, eliminar as últimas. Devem os magistrados "consumar un ehaustivo reciclaje del material normativo local" (SAGÜÉS, 2011, P. 385).

A ideia central do entendimento consolidado pela Corte Interamericana de Direitos Humanos referente a este segundo efeito é a de que o magistrado local deve começar sua análise legal do caso concreto partindo dos ditames estabelecidos pelas normas internacionais e pela jurisprudência da Corte e, somente em um segundo momento, partir para análise da legislação doméstica.

Mas conclui Saguiés (2011) que em qualquer dos dois efeitos acima elencados, seja como órgão repressivo, seja como órgão construtivo, o poder judiciário do Estado parte atua como um aplicador das diretrizes previamente enunciadas pelo Pacto San José da Costa Rica ou pela jurisprudência da Corte Interamericana. Todavia certamente haverão situações onde ainda não existam pronunciamentos da Corte. Nestes casos terá o magistrado local uma certa margem de criatividade. Certamente tais decisões não vincularão a Corte, mas poderão ser extremamente proveitosas para inspirar futuros pronunciamentos, impulsionando o que os europeus denominam de diálogo entre juízes.

Uma segunda característica do controle de convencionalidade que também precisa ser elucidada é sobre os sujeitos habilitados a praticá-lo.

Segundo aduz Sagués (2011), todos os órgãos do Poder Judiciário estão habilitados para praticar o controle de convencionalidade dentro de suas respectivas competências. Isto significa dizer que todos que detém competência para declarar a inconstitucionalidade das leis e atos normativos domésticos possuem também competência para declarar a inconvencionalidade.

Logicamente, se estamos falando em declaração de inconvencionalidade da legislação nacional estamos tratando do controle com efeitos destrutivos/repressivos, que é a forma que apresenta alguns importantes questionamentos. O controle com efeitos construtivos não apresenta dificuldades, já que não demanda anulação ou a inaplicação de qualquer legislação, mas simples releitura das normas vigentes e das interpretações dominantes, podendo, destarte, ser praticado por todos os órgãos judiciais nacionais.

O problema surge quando estamos diante de casos de necessidade de anulação ou inaplicabilidade da legislação nacional por ser incompatível com as normas pactuadas internacionalmente e o ordenamento jurídico nacional preveja que o controle da constitucionalidade das leis e atos normativos seja exercido unicamente pela Corte Constitucional, ou seja, não trate-se de Estado que adote o sistema do controle difuso ou 
híbrido de constitucionalidade. Nestes casos somente a Corte Constitucional estaria habilitada a praticá-lo.

Conforme assegura Sagiés (2011), é grande o número de autores que entendem que o controle de convencionalidade exigido pela Corte Interamericana é definitivamente o difuso, ainda que em sua dimensão repressiva. Segundo aduz o autor, uma nova leitura do considerando 128 do caso dos Trabajadores Cesados del Congreso mostra que não há ali uma exclusão do juiz local não habilitado a praticar o controle de constitucionalidade para que também se abstenha de praticar o de convencionalidade. Inclusive, completa o autor, que analisando o direito comparado, em especial no caso Simmenthal, a mesma conduta foi aconselhada pelo Tribunal de Justiça das comunidades europeias.

Mas se determinado Estado possui magistrados inabilitados a prática desse controle e nem sempre seja possível se chegar às instâncias superiores através das vias recursais, é imperativa a necessidade de se encontrar vias alternativas.

Sagüés (2010) propõe então três vias alternativas: a) antes de qualquer outra solução, de acordo com a espécie do problema, sempre tentar promover uma reforma constitucional ou legislativa; b) sendo impraticável tal reforma, reconhecer jurisprudencialmente que todo o poder judiciário tenha aptidão para exercer o controle de convencionalidade; c) elaborar, também de forma jurisprudencial, um mecanismo de elevação do caso ao órgão constitucionalmente programado para exercer este controle. E estas construções jurisprudenciais, completa o autor, não seriam vias ilegítimas de concretização de direito, haja vista, inclusive, o disposto no art. $2^{\circ}$ da Convenção Americana de Direitos Humanos, conforme anteriormente explicitado.

Mas enfim, a Corte Interamericana de Direitos Humanos vem exteriorizando seu entendimento de que os todos juízes nacionais atualmente estão compelidos, dentro de suas respectivas competências e regulações processuais, a realizar esse controle de convencionalidade. Nos últimos julgamentos, no entanto, pode-se dizer que houve um sensível alargamento nessa percepção dos sujeitos aptos a realizar o controle, de forma a abranger todos os órgãos oficiais.

A instrumentalização do controle de convencionalidade das leis é outra importante característica que merece destaque.

Preceitua o já mencionado considerando 128 do caso dos Trajadores Cesados del Congreso que o controle de convencionalidade exercido pelo juízes nacionais deve ser suscitado pelas a pedido da parte, mas também de ofício pelos magistrados. Para tanto, os 
juízes nacionais além de não poder desconhecer os ditames convencionais precisam estar atentos aos entendimentos consolidados pela Corte Interamericana.

O controle parte da ideia do estabelecimento de uma norma de referência/controlante (Pactos San José da Costa Rica) conjuntamente com a jurisprudência da Corte Interamericana, sempre efetuando um trabalho de comparação normativa, isto é, determinada norma, por sua importância normativa internacional, é elevada à condição norma parâmetro e toda a legislação constitucional e infraconstitucional nacional deve a ela se conformar. Tal possibilidade de subordinação do texto constitucional veio à lume com o caso dos Trabajadores Cesados del Congreso, de forma inovadora em relação à Almonacid Arellano. Enquanto este assinalou que o controle de convencionalidade se praticava sobre as leis contrárias ao objeto e fins da Convenção, esse assinalou que incluiria no material passível de ser controlado a normas jurídicas internas, sem diferenciar as infra das constitucionais.

Neste diapasão, Sagués (2011) assegura que o controle de convencionalidade está pressupondo que o material normativo utilizado como parâmetro é juridicamente superior ao controlado, o que traduziria o que a doutrina vem chamando de supremacia convencional. Princípio este que é alvo de inúmeras críticas, mormente nos países em que a Constituição em acima dos Pactos. Hoje é assente na Corte que o Pacto vale juridicamente mais que a Constituição, muito embora haja fortíssima resistência por parte dos Estados signatários e a Convenção não estabeleça tal preceito nestes exatos termos.

Mas sempre lembrando que, coforme discutido outrora, o controle de convencionalidade pode também ocorrer a partir de outras normas internacionais parâmetro que não o Pacto de San José da Costa Rica. É perfeitamente possível, seguindo entendimnto de Sagüés (2011), que este controle seja também exercido pelo juízes nacionais com base no Pacto Internacional de Direitos Civis e Políticos ou mesmo no Pacto Internacional de Direitos Econômicos, Sociais e Culturais.

\section{CONTRIBUIÇÕES}

Aspecto merecedor de destaque trazido pela implementação do controle de convencionaliade é a facilitação do diálogo e da cooperação internacional através da atuação dos magistrados singulares. Segundo afirma Alcalá (2012), o juiz nacional de primeiro grau 
de jurisdição é o juiz natural da Corte Interamericana de Direitos Humanos e do corpus iuris interamericano e quem deve ser o primeiro aplicador do controle de convencionalidade.

Logicamente, e da mesma forma como se deixou claro outrora, o juiz nacional como juiz do corpus iuris interamericano atua embasado no princípio da subsidiariedade da jurisdição interamericana, o que significa dizer que deve aplicar a legislação convencional somente se for mais benéfica ao ser humano. O que a legislação internacional traz são meros standards mínimos de proteção, o que obviamente não impede os Estados ir mais além e assegurar e garantir em seus ordenamentos jurídicos direitos com standards mais altos que os por ela consignados.

É tarefa do magistrado nacional conhecer e resolver a contenda antes dela chegar na Corte. E isso ocorre, segundo assegura Geert Corstens (apud ALCALÁ, 2012), porque a proteção aos direitos humanos positivados pela Convenção compete em primeiro lugar aos próprios Estados.

Para isso o juiz de primeiro grau pode liberar-se do seu dever de estar adstrito à legislação interna quando esta mostrar-se violadora do direito convencional, podendo, até mesmo, retirar a eficácia dos efeitos negativos de determinada legislação ou ato administrativo incompatível com os direitos fundamentais pactuados internacionalmente. E essa possibilidade de distanciamento da legislação interna faz com que os magistrados singulares possam adequar seu ordenamento jurídico aos padrões mínimos convencionais sem ter que sofrer condenações no plano internacional.

E toda essa readequação do ordenamento jurídico interno de acordo com os padrões mínimos estabelecidos pela Convenção Americana de Direitos Humanos traz consigo uma uniformização da legislação de todos os países que dela são integrantes, reduzindo, assim, grande parte das discrepâncias usualmente verificadas nos critérios de proteção e garantia da dignidade da pessoa humana.

Pode-se dizer, diante de tudo isso, que essa nova forma de controle da legislação nacional é uma nova arma colocada nas mãos dos magistrados nacionais de todas as instâncias em prol da defesa e garantia dos direitos humanos. Pode-se afirmar também que este controle reforça a posição do juiz nacional em relação aos demais órgãos estatais, já que passa a deter condições de limitação legislativa que anteriormente nem a Suprema Corte Constitucional era detentora.

A proteção internacional dos direitos humanos também possibilita uma tutela de caráter multinível, ou seja, que consegue escapar das amarras estatais e, assim, dar à normativa interna uma dimensão ao menos equivalente aos padrões mínimos estabelecidos 
pela Convenção Americana de Direitos Humanos e pela interpretação realizada pela Corte Interamericana de Direitos Humanos.

\begin{abstract}
La protección de los derechos fundamentales por los ordenamientos nacionales e internacional y por los tribunales nacionales y la Corte Interamericana, potencia tales derechos en esta tutela de carácter multinivel, jurisdicción ordinaria o especial, Tribunal Constitucional y Corte Interamericana de Derechos Humanos, lo que establece una combinación de carácter virtuoso, generando la obligación del legislador nacional de adecuarse a los principios mínimos que exige el derecho convencional de derechos humanos determinados por el corpus iuris interamericano para no generar responsabilidad por violación de derechos humanos por parte del Estado legislador, dando a la normativa interna una dimensión al menos equivalente al estándar mínimo exigido por la $\mathrm{CADH}$ y la interpretación concretada por la CIDH, y la obligación del Tribunal Constitucional en la hipótesis de que sea imposible una interpretación adecuadora, de no consentir que pueda continuar aplicándose y teniendo eficacia en el ordenamiento jurídico chileno una norma jurídica legal o administrativa que contenga un déficit de aseguramiento y garantía de un derecho fundamental inferior a la exigida por el estándar mínimo interamericano. Ello implica que el Tribunal Constitucional debe integrar necesariamente al parámetro de control de constitucionalidad los estándares mínimos respecto de atributos y garantías de los derechos asegurados por el sistema interamericano, utilizando el principio "pro homine" o "favor persona". Ello posibilita al Tribunal Constitucional realizar simultáneamente el control de constitucionalidad exigido constitucionalmente y el control de convencionalidad exigido por el sistema interamericano, posibilitando así los plus de protección de derechos que estén contenidos tanto en la Constitución como en el corpus iuris interamericano (ALCALÁ, 2012, P. 85).
\end{abstract}

Deve, o poder judiciário nacional como um todo, ter uma postura ativa de cooperação e de coordenação voluntária com a Corte Interamericana, sempre buscando compreender o espírito das soluções jurisprudenciais tomadas por ela tomadas, bem como assumindo uma atitude ativa de interpretação e aplicação das normas convencionais em face do direito doméstico.

Além da ampliação do diálogo entre juízes nacionais e a Corte Interamericana e da instituição de uma tutela de caráter multinível, uma outra contribuição de grande relevância quando se está a procura de efetividade da legislação convencional é a possibilidade de responsabilização internacional do Estado.

Seguindo a mesma lógica que rege as relações sociais dos cidadãos nacionais, os sujeitos de direito internacional não podem esquivar-se de responder por quaisquer danos que venham a causar aos seus pares. Segundo estabelece o art. $1^{\circ}$ do projeto (ainda em discussão no âmbito das Nações Unidas) de Convenção Internacional sobre Responsabilidade Internacional do Estado, tal responsabilidade é princípio próprio do direito das gentes, consolidando a ideia de que todo fato internacionalmente ilícito praticado por determinado Estado gera a sua responsabilidade internacional. 
Segundo assegura Mazzuoli (2007), essa responsabilidade estatal pode ser conceituada como um instituto jurídico que objetiva atribuir responsabilidade à determinado Estado pela prática de um ato atentatório ao Direito Internacional perpetrado em face dos direitos ou dignidade de outro Estado, prevendo uma determinada reparação a este por todos os prejuízos que lhe foram acarretados. Mas é preciso ter em mente, conforme conclui Mazzuoli (2007), que tal responsabilidade aplica-se igualmente nas relações dos Estados com as pessoas sujeitas à sua jurisdição, especialmente quando se está tratando de violações à direitos humanos.

Este instituto da responsabilidade internacional visa sempre a reparação de um prejuízo causado a um Estado que decorre do cometimento de um ilícito praticado por outro. Ou seja, visa sempre a restauração do stato quo ante. Mas muito embora a reparação do prejuízo perpetrado seja sua missão primordial, nem sempre é possível o retorno ao estado anterior, sendo necessário a substituição de tal reparação por uma indenização ou compensação.

Mas a experiência denota que é muito mais recorrente na história das relações internacionais a compensação pecuniária do que qualquer medida reparatória. Dessa forma, a questão que parece preocupar mais os internacionalistas é saber quais os critérios adequados para se chegar a uma indenização justa. A única questão já pacificada é que os lucros cessantes e os juros de mora certamente estão incluídos nesta justa indenização.

De outra banda, relata Mazzuoli (2007) que a responsabilidade penal do Estado é quase desconhecida internacionalmente, especialmente quando se fala em imposição de penas, castigos ou outras formas de repressão criminal congêneres. Tem lugar, unicamente, nos casos de genocídio, crimes de guerra e de crimes contra humanidade.

E para além da responsabilidade internacional do Estado, Alcalá (2012) faz expressa menção à responsabilidade do judiciário nacional. Aduz o autor que o art. $2^{\circ}$ da Convenção Americana de Direitos Humanos ao mencionar "medidas (...) de outra natureza" quer dizer que os órgãos judiciários nacionais, enquanto órgãos do Estado, se encontram vinculados direta ou indiretamente com os direitos assegurados convencionalmente. Ou seja, os direitos pactuados no âmbito internacional não podem ser mitigados não só no plano legislativo, mas também em tantos outros planos quanto se fizer necessário, como é o caso do próprio judiciário.

Nesse sentido, cada vez que o magistrado nacional deixa de aplicar, dentro de suas competências e de acordo com os procedimentos internacionalmente estabelecidos, direito convencional garantidor de direitos fundamentais está praticando ato que carece de valor 
jurídico e que é contrário ao direito. E ao praticar ato de tal magnitude, estará ensejando a responsabilidade internacional do Estado, haja vista que, enquanto magistrado, é agente estatal e está insculpido de prerrogativas estatais.

\section{CONCLUSÃO}

Portanto, com da análise do exposto percebe-se que a teoria do Controle de Convencionalidade das leis é fundamental para a idealização de um ordenamento jurídico que esteja continuamente dialogando com a ordem internacional, no sentido de promover a contenção da produção legislativa interna que esteja em desacordo com os compromissos internacionalmente assumidos, bem como também no sentido de condicionar a atuação do judiciário nacional aos ditames convencionais.

Trata-se de uma sistemática de grande relevância quando se está abordando a proteção dos direitos humanos e fundamentais, haja vista a possibilidade de inserção de padrões humanitários mínimos estabelecidos no plano internacional como requisitos materiais para a produção legislativa e também como norte para a atuação jurisdicional.

Suas maiores e mais importantes contribuições para a formação de um ius commune latino-americano de base humanitária são basicamente três: (1) facilitação do diálogo internacional através da atuação dos juízes singulares nacionais, o que significa uma atuação de ofício dos magistrados de primeiro grau e já caminhando ao encontro dos pactos internacionais e das decisões da Cortes Internacionais; (2) implementação de uma tutela de caráter multinível, ou seja, uma possibilidade de recorrer-se às Cortes Internacionais quando os magistrados das instâncias inferiores ou mesmo das superiores não dialogarem com os padrões humanitários internacionalmente estabelecidos; e (3) legitimação e imputação de responsabilidade internacional aos Estados violadores de direitos internacionalmente pactuados.

Todavia trata-se de uma ferramenta ainda muito pouco utilizada e conhecida pelos operadores jurídicos brasileiros. Mesmo que já venha sendo tratada desde a década de 1980 pela Corte Européia de Direitos Humanos e de pelo menos 2006 de forma pacífica no âmbito da Corte Interamericana de Direitos Humanos ainda é muito pouco lembrada.

Tanto assim é que ao se pesquisar na jurisprudência do Tribunal de Justiça do Estado do Rio Grande do Sul o termo "convencionalidade" surgem apenas oito ementas envolvendo 
tal expressão, todas do mesmo relator e datadas de 2013, o que demonstra a pouca popularidade do tema bem como sua recente integração ao ambiente jurídico brasileiro. Já na jurisprudência do Tribunal Regional do Trabalho da $4^{\mathrm{a}}$ Região e na do Tribunal Regional Federal da $4^{\text {a }}$ Região a questão foi ainda menos tratada, com apenas uma ementa envolvendo a expressão "convencionalidade" em cada um dos âmbitos. ${ }^{1}$

Por tudo isso, é preciso que haja urgentemente uma atualização e uma conscientização do Poder Judiciário brasileiro como um todo para que tão importantes contribuições humanitárias sejam plenamente efetivadas e capazes de esgotar inteiramente seu potencial emancipatório.

\section{REFERÊNCIAS}

ALCALÁ, Humberto Nogueira. Diálogo Interjurisdiccional, control de convencionalidad y jurisprudencia del tribunal constitucional en período 2006-2011. In: Estudios

Constitucionales. Año 10, $\mathrm{n}^{\circ}$ 2, 2012. P. 57-140. Disponível em:

http://www.scielo.c1/pdf/estconst/v10n2/art03.pdf. Acesso em: 15 abr. 2013.

BASTOS JUNIOR, Luiz Magno Pinto; CAMPOS, Thiago Yukio Guenka. Para além do debate em torno da hierarquia dos tratados: do duplo controle vertical das normas internas em razão da incorporação dos tratados de direitos humanos. In: RFD - Revista da Faculdade de Direito da UERJ. Vol. 1, no 19, jun./dez. 2011. Disponível em: $<$ http://www.epublicacoes.uerj.br/index.php/rfduerj/article/view/1717/1331>. Acesso em: 25 mar. 2013.

JINESTA, Ernesto. Control de Convencionalidad Ejercido por los Tribunales y Salas Constitucionales. In Mac-Gregor, Ferrer (coord.) El control difuso de convencionalidad, México, Fundap, 2012. Disponível em: <http://www.ernestojinesta.com/14\%20$\% 20$ Control $\% 20 \mathrm{de} \% 20$ Convencionalidad $\% 20$ Ejercido $\% 20$ por $\% 2010$ \% $\% 20$ Tribunales $\% 20 \mathrm{y} \%$ 20Salas\%20Constitucionales.pdf $>$. Acesso em: 17 mai. 2013.

MARCONI, M. de A.; LAKATOS, E. M. Fundamentos de metodologia científica. 7. ed. São Paulo: Atlas, 2010.

MAZZUOLI, Valério de Oliveira. O controle juris dicional da convencionalidade das leis. São Paulo: Editora Revista dos Tribunais, 2009.

\footnotetext{
1 Consulta jurisprudencial realizada em dezembro de 2013.
} 
Curso de direito internacional público. $2^{\circ}$ Ed. São Paulo: Editora Revista dos Tribunais, 2007.

PIOVESAN, Flávia. Direitos Humanos e o Direito Constitucional Internacional. 13ª Ed., ver. e atual. - São Paulo: Saraiva, 2012.

SAGÜÉS. Nestor Pedro. El "control de convencionalidad" en el sistema interamericano, y SUS antecipos en el âmbito de los derechos económicos-sociales. Concordancias y diferencias com el sistema europeo. In: BOGDANDY, Armin Von; FIX-FIERRO, Héctor; ANTONIAZZI, Mariela Morales; MAC-GREGOR, Eduardo Ferrer (orgs). Construcción y Papel de los Derechos Sociales Fundamentales. $1^{\text {a }}$ Ed., Universidad Nacional Autônoma de México, Instituto de Investigaciones Jurídicas, 2011. Disponível em: <

http:/www.ijf.cjf.gob.mx/cursosesp/2012/derhumancontrolconvencionalidad/Nestor\%20Sagu es.pdf $>$. Acesso em: 20 fev. 2013.

Obligaciones internacionales y control de convencionalidad. In: Estudios constitucionales, año 8, nº 1, 2010. P. 117-136. Disponível em: <

http://www.cecoch.cl/docs/pdf/revista_ano8_1_2010/articulo_4.pdf $>$. Acesso em: 04 mar. 2013.

SANTOS, Boaventura de Sousa. A crítica da razão indolente: contra o desperdício da existência. $2^{\text {a }}$ Ed. V 1. São Paulo: Cortez, 2000.

WOLKMER, Antonio Carlos. Pluralismo jurídico: fundamentos de uma nova cultura no Direito. $3^{\text {a }}$ ed. rev. e atual. São Paulo: Editora Alfa Omega, 2001. 